\title{
Evaluation of antivenoms in the neutralization of hyperalgesia and edema induced by Bothrops jararaca and Bothrops asper snake venoms
}

\section{G. Picolo ${ }^{1}$, M. Chacur ${ }^{1}$, \\ J.M. Gutiérrez ${ }^{3}$, \\ C.F.P. Teixeira ${ }^{2}$ and Y. Cury ${ }^{1}$}

\author{
Laboratórios de ${ }^{1}$ Fisiopatologia and ${ }^{2}$ Farmacologia, \\ Instituto Butantan, São Paulo, SP, Brasil \\ IInstituto Clodomiro Picado, Facultad de Microbiología, \\ Universidad de Costa Rica, San José, Costa Rica
}

\section{Correspondence \\ Y. Cury \\ Laboratório de Fisiopatologia \\ Instituto Butantan \\ Av. Vital Brazil, 1500 \\ 05503-900 São Paulo, SP \\ Brasil \\ Fax: +55-11-3726-1505 \\ E-mail: yarac@attglobal.net}

Research supported by FAPESP (No. 98/00257-0), Fundação Butantan and Vicerrectoría de Investigación, Universidad de Costa Rica (Project 741-A1-027).

Received November 26, 2001 Accepted July 12, 2002

\section{Abstract}

Neutralization of hyperalgesia induced by Bothrops jararaca and B. asper venoms was studied in rats using bothropic antivenom produced at Instituto Butantan (AVIB, $1 \mathrm{ml}$ neutralizes $5 \mathrm{mg}$ B. jararaca venom) and polyvalent antivenom produced at Instituto Clodomiro Picado (AVCP, $1 \mathrm{ml}$ neutralizes $2.5 \mathrm{mg} \mathrm{B}$. aspar venom). The intraplantar injection of $B$. jararaca and $B$. asper venoms caused hyperalgesia, which peaked 1 and $2 \mathrm{~h}$ after injection, respectively. Both venoms also induced edema with a similar time course. When neutralization assays involving the independent injection of venom and antivenom were performed, the hyperalgesia induced by $B$. jararaca venom was neutralized only when bothropic antivenom was administered iv 15 min before venom injection, whereas edema was neutralized when antivenom was injected 15 min or immediately before venom injection. On the other hand, polyvalent antivenom did not interfere with hyperalgesia or edema induced by $B$. asper venom, even when administered prior to envenomation. The lack of neutralization of hyperalgesia and edema induced by $B$. asper venom is not attributable to the absence of neutralizing antibodies in the antivenom, since neutralization was achieved in assays involving preincubation of venom and antivenom. Cross-neutralization of AVCP or AVIB against B. jararaca and $B$. asper venoms, respectively, was also evaluated. Only bothropic antivenom partially neutralized hyperalgesia induced by $B$. asper venom in preincubation experiments. The present data suggest that hyperalgesia and edema induced by Bothrops venoms are poorly neutralized by commercial antivenoms even when antibodies are administered immediately after envenomation.
Key words

- Bothrops jararaca venom

- Bothrops asper venom

- Hyperalgesia

- Edema

- Antivenom

- Neutralization 


\section{Introduction}

Antivenoms of equine or ovine origin constitute the only effective treatment of snakebite envenomation (1). The use of these products has greatly contributed to the reduction of mortality owing to their effectiveness in the neutralization of life-threatening, systemically acting toxins present in snake venoms (2-4). Randomized controlled clinical trials have demonstrated that antivenoms are highly effective in halting systemic bleeding, coagulopathies and other cardiovascular disturbances due to envenomations by snakes of the family Viperidae in Latin America (3,5-7).

In contrast, the effectiveness of antivenoms in neutralizing local effects induced by pit viper venoms is doubtful. Experimental studies have suggested that there is significant, albeit partial, neutralization of hemorrhage, edema, dermonecrosis and myonecrosis only when antivenom is administered rapidly after envenomation (8-10), even when using antibody fragments $\mathrm{F}(\mathrm{ab})_{2}$ and $\mathrm{Fab}$ which have a larger volume of distribution and reach the interstitial fluid at a faster rate $(11,12)$. Clinical observations also indicate that local tissue damage is only partially halted by antivenoms $(2,3,13)$.

Most experimental studies concerning neutralization of local effects have dealt with myonecrosis, hemorrhage and edema (for a review, see Ref. 10), but little attention has been paid to the study of pain, which is a clinically relevant consequence of snakebites and occurs in the vast majority of patients bitten by Bothrops sp $(3,13,14)$. Pharmacological studies carried out with $B$. jararaca and $B$. asper venoms have indicated that the hyperalgesic effect is based on the action of a number of inflammatory mediators such as leukotrienes, prostaglandins and platelet-activating factor, in the case of $B$. jararaca (15), and bradykinin and leukotrienes in the case of B. asper (16). However, there have been no investigations on the ability of antivenoms to neutralize this effect. The present study was designed to assess the neutralization of the hyperalgesic effect induced by $B$. asper and B. jararaca venoms by polyspecific antivenoms used clinically in Central and South America. For comparative purposes, the neutralizing ability of antivenoms against edema induced by both venoms was also investigated.

\section{Material and Methods}

\section{Animals}

Male Wistar rats weighing 170 to $190 \mathrm{~g}$ were maintained under controlled temperatures $\left(22-25^{\circ} \mathrm{C}\right)$ and on a 12-h light/dark cycle, with free access to food and water.

\section{Venoms}

Lyophilized crude venom of $B$. jararaca (BjV) was supplied by Laboratório de Herpetologia, Instituto Butantan, São Paulo, SP, Brazil, and lyophilized crude venom of $B$. asper $(\mathrm{BaV})$ was supplied by Instituto Clodomiro Picado, Costa Rica. Both venoms were kept at $-20^{\circ} \mathrm{C}$ and dissolved in sterile $0.15 \mathrm{M} \mathrm{NaCl}$ (saline solution) at the time of use.

\section{Antivenoms}

Bothropic antivenom of Instituto Butantan, batches 9710158 and 9805055 (AVIB anti- $B$. jararaca, anti- $B$. jararacussu, anti$B$. moojeni, anti- $B$. neuwiedii and anti- $B$. alternatus), and polyvalent antivenom of Instituto Clodomiro Picado, batch 2811096 (AVCP - anti-B. asper, anti-C.d. durissus and anti-L.m. stenophrys) were used in this study. Antivenoms were stored at $4^{\circ} \mathrm{C}$. The immunization protocols and adjuvants used have been previously described by Raw et al. (17) and Angulo et al. (18). Both antivenoms were liquid preparations used before their expiration date. 


\section{Evaluation of hyperalgesia}

The animals were injected with $5 \mu \mathrm{g}$ of $\mathrm{BjV}$ or $15 \mu \mathrm{g}$ of $\mathrm{BaV}$ dissolved in $100 \mu \mathrm{l}$ sterile saline solution into the subplantar surface of one hind paw. Control animals were injected with the same volume of sterile saline. The contralateral paw was not injected. The pain threshold was measured at 1 and $4 \mathrm{~h}$ or 2 and $4 \mathrm{~h}$ after $\mathrm{BjV}$ and $\mathrm{BaV}$ injection, respectively, or after saline injection using an Ugo-Basile pressure apparatus, essentially as described by Randall and Selitto (19). Briefly, a force (in g) of increasing magnitude was applied to the paw. The force needed to induce the rat to withdraw its paw was recorded and represented the pain threshold.

\section{Evaluation of edema formation}

Rats received an injection of $5 \mu \mathrm{g} \mathrm{BjV}$ or $15 \mu \mathrm{g} \mathrm{BaV}$ dissolved in $100 \mu \mathrm{l}$ sterile saline solution $(0.15 \mathrm{M} \mathrm{NaCl})$ into the subplantar surface of one hind paw. An equal volume of saline was injected into the contralateral paw (control). The volume increase (edema) of the paws was measured plethysmographically at 1 and $4 \mathrm{~h}$ or 2 and $4 \mathrm{~h}$ after $\mathrm{BjV}$ and $\mathrm{BaV}$ injection, respectively, according to the method of Van Arman et al. (20). The difference between the values obtained for both paws expressed as percent increase in paw volume was used as a measure of edema.

\section{Neutralization studies}

Two kinds of experiments were performed: 1) injection of antivenom at different times before or after venom administration and 2) in vitro incubation of venom and antivenom before injection.

Assays with independent injection of venom and antivenom. Antivenoms (0.5 ml) were administered iv 15 min or immediately before or $15 \mathrm{~min}$ after intraplantar injection of the venoms. Hyperalgesia and edema measurements were carried out as described above.

Assays with preincubation of venom and antivenom. A constant amount of venom was incubated with several dilutions of antivenom at the following antivenom/venom ratios: $1,0.5,0.25,0.125 \mathrm{ml}$ antivenom $/ \mathrm{mg}$ venom. After incubation at $37^{\circ} \mathrm{C}$ for $30 \mathrm{~min}$, $100 \mu \mathrm{l}$ of each mixture containing the appropriate amounts of venoms $(5 \mu \mathrm{g} \mathrm{BjV}$ or $15 \mu \mathrm{g}$ $\mathrm{BaV}$ ) were injected by the intraplantar route, and hyperalgesia and edema were determined as described above.

Cross-neutralization studies. Crossneutralization experiments were performed in order to determine if AVIB and AVCP antivenoms are able to neutralize the hyperalgesic and edematogenic effects induced by $B$. asper and B. jararaca venoms, respectively. The neutralization studies were carried out as described above for assays with independent injection of venom and antivenom or assays with preincubation of venom and antivenom. In preincubation assays, the antivenom/venom ratios used were $2 \mathrm{ml}$ antivenom/mg venom for $\mathrm{AVCP} / \mathrm{BjV}$ and $1 \mathrm{ml}$ antivenom/mg venom for $\mathrm{AVIB} / \mathrm{BaV}$.

The antivenoms did not alter, per se, the pain threshold of the animals, nor did they induce an edematogenic response (data not shown).

\section{Statistical analysis}

Data were analyzed statistically by analysis of variance and sequential differences among means were determined by Tukey contrast analysis, with the level of significance set at $\mathrm{P}<0.05$ (21).

\section{Results}

\section{Neutralization of hyperalgesia and edema induced by Bothrops jararaca venom}

The intraplantar injection of $\mathrm{BjV}(5 \mu \mathrm{g}$ ) paw) into the rat hind paw caused a signifi- 
Figure 1. Neutralization of the hyperalgesia and edema activity of Bothrops jararaca venom by bothropic antivenom in assays in which venom and antivenom were injected separately. Antivenom (AV, $0.5 \mathrm{ml}, 15 \mathrm{mg}$ protein) or saline control (S, $0.5 \mathrm{ml})$ was injected iv $15 \mathrm{~min}$ before, immediately before or 15 min after intraplantar injection of the venom ( $V, 5 \mu \mathrm{g} / \mathrm{paw})$. The decrease in threshold response $(A)$ and increase in paw volume (B) were determined in rat hind paws before and 1 and $4 \mathrm{~h}$ after injection of the venom. Sensitivity to pain was measured as the threshold response to pressure and is reported in grams. Edema is reported as percent increase in relation to the initial volume of the paw. $\mathrm{V}+\mathrm{S}$ (squares); $\mathrm{V}+\mathrm{AV}$ $15 \mathrm{~min}$ before (filled circles); $\mathrm{V}+$ AV immediately before (open circles) or V + AV 15 min after (triangles). Each point indicates the mean \pm SEM for 6 animals. $* P<0.05$ compared to the $S+V$ group (ANOVA followed by Tukey test). Note that the abscissa scale is not linear.

Figure 2. Neutralization of the hyperalgesia and edema induced by Bothrops jararaca venom by bothropic antivenom in assays in which venom and antivenom were incubated together before injection into the rat paw. The same amount of venom $(\mathrm{V}, 5 \mu \mathrm{g} / \mathrm{paw})$, was incubated with various dilutions of antivenom (AV) or with saline (S, control) for $30 \mathrm{~min}$ at $37^{\circ} \mathrm{C}$. Then, $100 \mu \mathrm{l}$ of the mixtures containing $5 \mu \mathrm{g}$ of venom were injected by the intraplantar route. The decrease in threshold response (A) and increase in paw volume (B) were determined in rat hind paws before and 1 and $4 \mathrm{~h}$ after injection of the venom. Sensitivity to pain was measured as the threshold response to pressure and is reported in grams. Edema is reported as percent increase in relation to the initial volume of the paw. Each point indicates the mean \pm SEM for 6 animals. $* \mathrm{P}<0.05$ compared to the $\mathrm{S}+\mathrm{V}$ group (ANOVA followed by Tukey test). Note that the abscissa scale is not linear. cant decrease in pain threshold (hyperalgesia) and an increase in paw volume. The peak of the hyperalgesic and edematogenic responses occurred $1 \mathrm{~h}$ after venom injection. After this time both phenomena started to decrease (Figure 1) and completely disappeared at $24 \mathrm{~h}$ (data not shown). When venom and antivenom were injected separately, neutralization of $\mathrm{Bj} \mathrm{V}$-induced hyperalgesia was observed only when AVIB was administered $15 \mathrm{~min}$ before venom injection (Figure 1A). Administration of AVIB 15 min or immediately before $\mathrm{BjV}$ induced a marked reduction of edema, although this effect was not completely neutralized (Figure 1B).

In experiments with incubation of venom and antivenom prior to injection, antivenom was effective in neutralizing the hyperalgesia and edema induced by $\mathrm{BjV}$ (Figure 2). Full protection against hyperalgesia was achieved at antivenom/venom ratios of $5 \mu \mathrm{l} /$ $5 \mu \mathrm{g}(1 \mathrm{ml} / \mathrm{mg})$ and $0.625 \mu \mathrm{l} / 5 \mu \mathrm{g}(0.125 \mathrm{ml} /$ $\mathrm{mg}$ ) (Figure 2A), whereas edema was significantly reduced but not abolished at the same antivenom/venom ratios (Figure 2B).

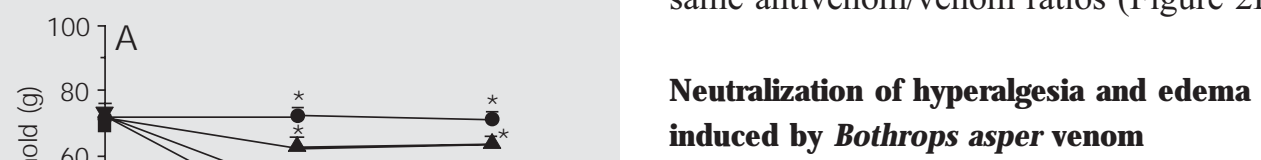

The intraplantar injection of $\mathrm{BaV}(15 \mu \mathrm{g} /$ paw) induced hyperalgesia and edema which peaked $2 \mathrm{~h}$ after venom injection, decreasing thereafter (Figure 3). AVCP administered $15 \mathrm{~min}$ or immediately before or $15 \mathrm{~min}$ after B. asper venom injection did not modify the hyperalgesia or edema induced by the venom (Figure 3). In experiments involving preincubation, AVCP neutralized hyperalgesia at the antivenom/venom ratio of $3.75 \mu \mathrm{l} / 15 \mu \mathrm{g}$ $(0.250 \mathrm{ml} / \mathrm{mg})$, whereas a partial neutralization of edema was observed at the antivenom/venom ratio of $15 \mu \mathrm{l} / 15 \mu \mathrm{g}(1 \mathrm{ml} / \mathrm{mg})$ (Figure 4).

\section{Cross-neutralization studies}

AVIB or AVCP injected 15 min before 
$\mathrm{BaV}$ and $\mathrm{BjV}$, respectively, did not modify the hyperalgesia or edema induced by both venoms (data not shown). In experiments involving incubation of venom and antivenom prior to injection, AVIB partially neutralized the hyperalgesia and edema induced by $\mathrm{BaV}$ (Figure 5A,B). On the other hand, AVCP did not modify either effect induced by $B$. jararaca venom. One hour after intraplantar injection of neutralized venom, the pain threshold was $47 \pm 1.2 \mathrm{~g}$ and the increase in paw volume was $64 \pm 8 \%$. The data for the control (non-neutralized venom) group were $53 \pm 2 \mathrm{~g}$ for pain threshold and $47 \pm 8 \%$ for paw volume increase.

\section{Discussion}

Bothropic and polyvalent antivenoms constitute the major therapeutic resource in snakebite envenomations in Brazil and Central America, respectively $(3,22)$. Clinical investigations have demonstrated the efficacy of these products on the neutralization of life-threatening systemic effects associated with these envenomations $(3,5,14)$. However, experimental and clinical evidence indicates that local effects in Bothrops sp envenomations are poorly neutralized by these and other antivenoms $(3,8,10,13)$. The present results further demonstrate the complete ineffectiveness of these antivenoms in neutralizing the local edema and hyperalgesia induced by $B$. asper and $B$. jararaca venoms when antivenoms are administered to rats after envenomation.

The ability of antivenoms to neutralize hyperalgesia has not been previously addressed in experimental studies, despite the fact that pain is a common manifestation of Bothrops sp envenomations $(3,13,23)$. We selected venom doses which caused an increase in the sensitivity to pain (hyperalgesia) and local edema, without inducing macroscopically evident hemorrhage or tissue damage. Such doses have been validated and used in previous pharmacological stud-
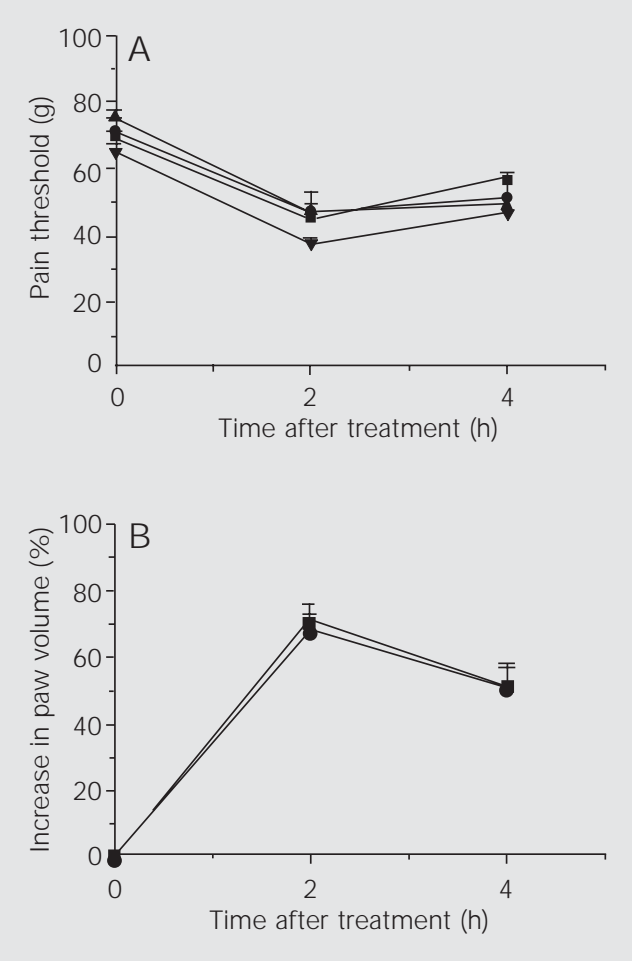

Figure 3. Neutralization of the hyperalgesia and edema activity of Bothrops asper venom by polyvalent antivenom in assays in which venom and antivenom were injected separately. Antivenom (AV, $0.5 \mathrm{ml}, 22 \mathrm{mg}$ protein) or saline (S, control group) was injected iv $15 \mathrm{~min}$ before, immediately before or $15 \mathrm{~min}$ after intraplantar injection of the venom $(\mathrm{V}, 15 \mu \mathrm{g} / \mathrm{paw})$. The decrease in threshold response (A) and increase in paw volume (B) were determined in rat hind paws before and 2 and $4 \mathrm{~h}$ after injection of the venom. Sensitivity to pain was measured as the threshold response to pressure and is reported in grams. Edema is reported as percent increase in relation to the initial volume of the paw. $\mathrm{V}+\mathrm{S}$ (squares); $\mathrm{V}+\mathrm{AV}$ $15 \mathrm{~min}$ before (circles); $\mathrm{V}+\mathrm{AV}$ immediately before (triangles) or V + AV 15 min after (inverted triangles). Each point indicates the mean \pm SEM for 6 animals.

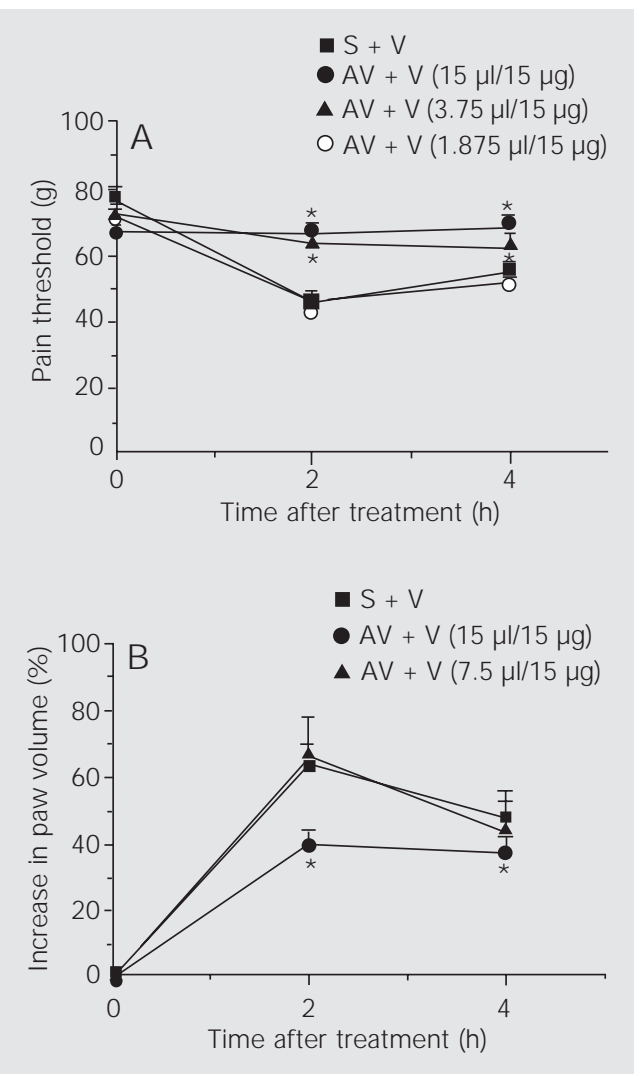

Figure 4. Neutralization of the hyperalgesia and edema induced by Bothrops asper venom by polyvalent antivenom in assays in which venom and antivenom were incubated together before injection into rats. A fixed amount of venom $(V)$ was incubated with various dilutions of antivenom (AV) or with saline (S, control) for $30 \mathrm{~min}$ at $37^{\circ} \mathrm{C}$. Then, $100 \mu \mathrm{l}$ of the mixtures containing $15 \mu \mathrm{g}$ of venom were injected by the intraplantar route. The decrease in threshold response (A) and increase in paw volume (B) were determined in rat hind paws before and 2 and 4 $\mathrm{h}$ after injection of the venom. Sensitivity to pain was measured as the threshold response to pressure and is reported in grams. Edema is reported as percent increase in relation to the initial volume of the paw. Each point indicates the mean \pm SEM for 6 animals. ${ }^{*} \mathrm{P}<0.05$ compared to the $\mathrm{S}+\mathrm{V}$ group (ANOVA followed by Tukey test). 
Figure 5. Neutralizing activity of bothropic antivenom (AVIB) against Bothrops asper venom in assays involving incubation of the venom and the antivenom together before injection. A fixed amount of venom was incubated with dilutions of antivenom or with saline (S, control) for $30 \mathrm{~min}$ at $37^{\circ} \mathrm{C}$. Then, $100 \mu \mathrm{l}$ of the mixture containing $15 \mu \mathrm{g}$ of $\mathrm{B}$. asper venom (BaV) was injected by the intraplantar route. The decrease in threshold response (A) and increase in paw volume (B) were measured in rat hind paws before and 2 and $4 \mathrm{~h}$ after the injection of BaV. Sensitivity to pain was measured as the threshold response to pressure and is reported in grams. Edema is reported as percent increase in relation to the initial volume of the paw. Each point indicates the mean \pm SEM for 6 animals. $* P<0.05$ compared to the $\mathrm{BaV}+$ $\mathrm{S}$ group (ANOVA followed by Tukey test).

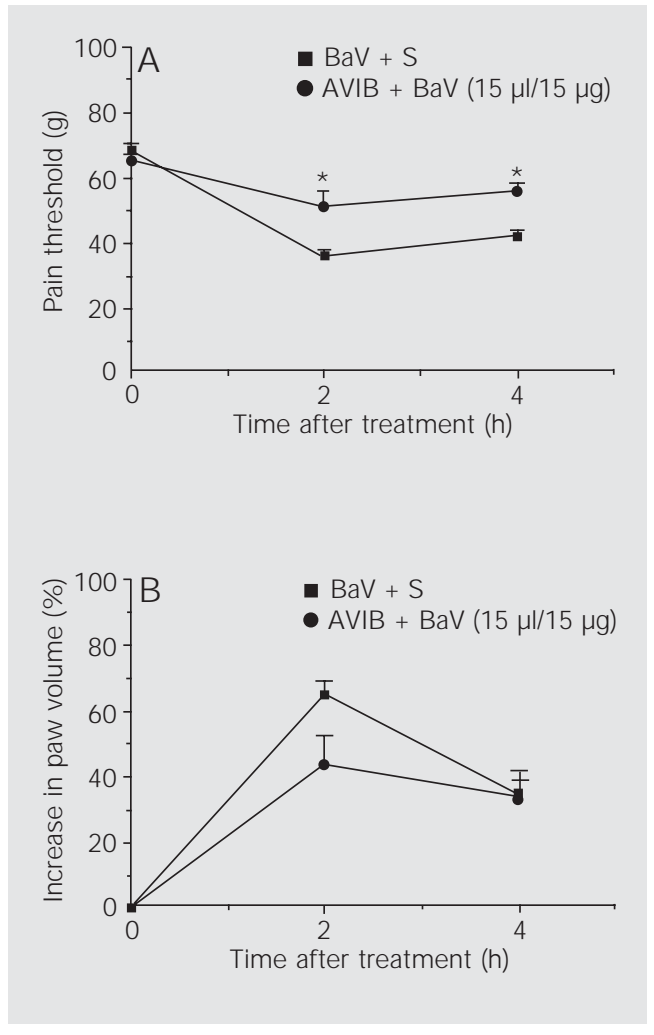

ies $(15,16)$.

Bothropic antivenom produced against $B$. jararaca at Instituto Butantan was ineffective in neutralizing edema or hyperalgesia when administered after envenomation. Only when antivenom was injected before venom was neutralization achieved. In the case of $B$. asper venom, polyvalent antivenom produced in Costa Rica was ineffective in neutralizing edema or hyperalgesia when administered either before or after envenomation, in agreement with prior observations in mice $(8,10)$. Moreover, Rucavado and Lomonte (24) demonstrated that the presence of antibodies in the circulation before injection of $B$. asper venom in mice reduces, but does not abolish, local tissue damage.

Such poor neutralizing efficacy cannot be explained on the basis of lack of neutralizing antibodies in these antivenoms, since both hyperalgesic and edematogenic responses were abolished if venom and antivenoms were incubated prior to injection. A similar situation occurs regarding the neutralization of hemorrhage and myonecrosis induced by $B$. asper venom (8-10). It has been suggested that the observed poor neutralization is based on the fact that hyperalgesia and edema develop at an extremely rapid rate after venom injection, associated with the release of endogenous mediators involved in these pharmacological effects $(15,16,25,26)$. Thus, by the time antivenom antibodies reach the affected tissues, it is likely that the cascade of inflammatory events associated with hyperalgesia and edema has already started. Moreover, since antivenoms are administered intravenously, the amount of antibodies diffusing to the affected tissues is probably insufficient and delayed. Thus, an evident mismatch occurs between the pharmacokinetics and pharmacodynamics of venoms and antivenoms in this experimental model and, very likely, in the clinical situation as well.

The present study also addressed the issue of cross-neutralization of these effects by antivenoms. Previous investigations have documented cross-neutralization between bothropic and polyvalent antivenoms when assayed against a variety of venoms from Central and South America (27-30). The present results demonstrate that bothropic antivenom partially neutralizes $B$. asper venom, whereas polyvalent antivenom is largely ineffective in the neutralization of edema and hyperalgesia induced by $B$. jararaca venom. It is likely that components immunologically related to hyperalgesic and edematogenic toxins in $B$. asper venom are present in one or more of the venoms included in the antigenic mixture used to produce bothropic antivenom in Brazil.

The present study reports the first experimental evidence showing that hyperalgesia induced by Bothrops sp venoms is not neutralized when antivenoms are administered after envenomation. In view of the clinical relevance of pain in Bothrops sp envenomations, it is necessary to gain further under- 
standing of the pharmacological mechanisms involved in this effect, as well as of the characteristics of the hyperalgesic compo- nents present in these venoms in order to develop therapeutic strategies aimed at controlling pain in these envenomations.

\section{References}

1. Warrell DA (1992). The global problem of snake bite: its prevention and treatment. In: Gopalakrishnakone P \& Tan CR (Editors), Recent Advances in Toxicology Research. National University of Singapore, Singapore, 121-153.

2. Rosenfeld G (1971). Symptomatology, pathology and treatment of snake bites in South America. In: Bucherl W \& Buckley $E$ (Editors), Venomous Animals and Their Venoms. Vol. II, Venomous Vertebrates. Academic Press, New York, NY, USA, 345-384.

3. Cardoso J LC, Fan HW, Franca FOS, J orge MT, Leite RP, Nishioka SA, Avila A, SanoMartins IS, Tomy SC, Santoro ML, Chudzinski AM, Castro SCB, Kamiguti AS, Kelen EMA, Hirata MH, Mirandola RMS, Theakston RDG \& Warrell DA (1993). Randomized comparative trial of three antivenoms in the treatment of envenoming by lance-headed vipers (Bothrops jararaca) in São Paulo, Brazil. Quarterly J ournal of Medicine, 86: 315-325.

4. Rojas G, Bogarín G \& Gutiérrez J M (1997). Snakebite mortality in Costa Rica. Toxicon, 35: 1639-1643.

5. Otero R, Gutiérrez J M, Núñez V, Robles A, Estrada R, Segura E, Toro MF, García ME, Díaz A, Ramírez EC, Gómez G, Castañeda J \& Moreno ME (1996). A randomized double-blind clinical trial of two antivenoms in patients bitten by Bothrops atrox in Colombia. Transactions of the Royal Society of Tropical Medicine and Hygiene, 90: 696-700.

6. Otero R, Gutiérrez J M, Rojas G, Núñez V, Díaz $A$, Miranda $E$, Uribe AF, Silva J F, Ospina J G, Medina Y, Toro MF, García ME, León G, García M, Lizano S, De La Torre J , Márquez J , Mena Y, González N, Arenas LC, Puzón A, Blanco N, Sierra A, Espinal ME, Arboleda M, J iménez JC, Ramírez P, Díaz M, Guzmán MC, Barros J , Henao S, Ramírez A, Macea U \& Lozano R (1999). A randomized blinded clinical trial of two antivenoms, prepared by caprylic acid and ammonium sulphate fractionation of IgG, in Bothrops and Porthidium snake bites in Colombia: correlation between safety and biochemical characteristics of antivenoms. Toxicon, 37: 895908.
7. Otero-Patiño R, Cardoso J LC, Higashi HG, Núñez V, Díaz A, Toro ME, García ME, Sierra A, García LF, Moreno AM, Medina MC, Castañeda N, Silva-Díaz J F, Murcia M, Cárdenas SY, Dias da Silva WD \& The Regional Group of Antivenom Therapy Research (REGATHER) (1998). A randomized, blinded, comparative trial of one pepsin-digested and two whole IgG antivenoms for Bothrops snake bites in Urabá, Colombia. American J ournal of Tropical Medicine and Hygiene, 58: 183-189.

8. Gutiérrez JM, Chaves F, Bolaños R, Cerdas L, Rojas E, Arroyo O \& Portilla E (1981). Neutralización de los efectos locales del veneno de Bothrops asper por un antiveneno polivalente. Toxicon, 19: 493-500.

9. Gutiérrez J M, Gené J A, Rojas G \& Cerdas $L$ (1985). Neutralization of proteolytic and hemorrhagic activities of Costa Rica snake venoms by a polyvalent antivenom. Toxicon, 23: 887-893.

10. Gutiérrez J M, León G, Rojas G, Lomonte B, Rucavado A \& Chaves F (1998). Neutralization of local tissue damage induced by Bothrops asper (terciopelo) snake venom. Toxicon, 36: 1529-1538.

11. León $\mathrm{G}$, Rojas $\mathrm{G}$, Lomonte $\mathrm{B} \&$ Gutiérrez J M (1997). IgG and $F\left(a b^{\prime}\right)_{2}$ polyvalent antivenoms do not differ in their ability to neutralize hemorrhage, edema and myonecrosis induced by Bothrops asper (terciopelo) snake venom. Toxicon, 35: 1627-1637.

12. León G, Valverde J M, Rojas G, Lomonte B \& Gutiérrez J M (2000). Comparative study on the ability of IgG and Fab sheep antivenoms to neutralize local hemorrhage, edema and myonecrosis induced by Bothrops asper (terciopelo) snake venom. Toxicon, 38: 233-244.

13. Otero R, Tobón GS, Gómez LF, Osorio RG, Valderrama R, Hoyos D, Urreta J E, Molina S \& Arboleda J J (1992). Accidente ofídico en Antioquia y Chocó. Aspectos clínicos y epidemiológicos (marzo de 1989-febrero de 1990). Acta Médica Colombiana, 17: 229-249.

14. Arroyo O, Rojas G \& Gutiérrez J M (1999). Envenenamiento por mordedura de serpiente en Costa Rica en 1996: epidemiología y consideraciones clínicas. Acta
Médica Costarricense, 41: 23-29.

15. Teixeira CFP, Cury $Y$, Oga $S \& J$ Jancar $S$ (1994). Hyperalgesia induced by Bothrops jararaca venom in rats: role of eicosanoids and platelet activating factor (PAF). Toxicon, 32: 419-426.

16. Chacur M, Picolo G, Gutiérrez J M, Teixeira CFP \& Cury Y (2001). Pharmacological modulation of hyperalgesia induced by Bothrops asper (terciopelo) snake venom. Toxicon, 39: 1173-1181.

17. Raw I, Guidolin R, Higashi HG \& Kelen EMA (1991). Antivenins in Brazil: preparation. In: Tu AT (Editor), Handbook of Natural Toxins. Vol. 5. Marcel Dekker, New York, NY, USA, 557-581.

18. Angulo $Y$, Estrada $R \&$ Gutiérrez J M (1997). Clinical and laboratory alterations in horses during immunization with snake venoms for the production of polyvalent (Crotalinae) antivenom. Toxicon, 35: 8190.

19. Randall LO \& Selitto JJ (1957). A method for measurement of analgesia activity on inflammed tissue. Archives Internationales de Pharmacodynamie, 111: 209219.

20. Van Arman CG, Begany AJ, Miller J M \& Pless HH (1965). Some details of the inflammation caused by yeast and carrageenin. J ournal of Pharmacology and Experimental Therapeutics, 150: 328-333.

21. Gad SC \& Weil CS (1989). Statistics for toxicologists. In: Hayer AW (Editor), Principles and Methods of Toxicology. 2nd edn. Raven Press, New York, NY, USA, 435-483.

22. Bolaños R \& Cerdas L (1980). Producción y control de sueros antiofídicos en Costa Rica. Boletin de la Oficina Sanitaria Panamericana, 88: 184-196.

23. Gutiérrez J M (1995). Clinical toxicology of snakebite in Central America. In: Meier J $\&$ White J (Editors), Handbook of Clinical Toxicology of Animal Venoms and Poisons. CRC Press, Boca Raton, FL, USA, 645-665.

24. Rucavado A \& Lomonte B (1996). Neutralization of myonecrosis, hemorrhage and edema induced by Bothrops asper snake venom by homologous and heterologous pre-existing antibodies in mice. Toxicon, 34: 567-577. 
25. Trebien HA \& Calixto J B (1989). Pharmacological evaluation of rat paw edema induced by Bothrops jararaca venom. Agents and Actions, 26: 292-300.

26. Chaves F, Barboza M \& Gutiérrez J M (1995). Pharmacological study of edema induced by venom of the snake Bothrops asper (terciopelo). Toxicon, 33: 31-39.

27. Dias da Silva W, Guidolin R, Raw I, Higashi HG, Caricati CP, Morais J F, Lima MLSR, Yamaguchi IK, Nishikawa AK, Stephano MA, Marcelino J R, Pinto J R \& Santos MJ
(1989). Cross-reactivity of horse monovalent antivenoms to venoms of ten Bothrops species. Memórias do Instituto Butantan, 51: 153-168.

28. Ferreira ML, Moura-da-Silva AM \& Mota I (1992). Neutralization of different activities of venoms from nine species of Bothrops snakes by Bothrops jararaca antivenom. Toxicon, 30: 1591-1602.

29. Bogarín G, Morais J F, Yamaguchi IK, Stephano MA, Marcelino J R, Nishikawa AK, Guidolin R, Rojas G, Higashi HG \&
Gutiérrez J M (2000). Neutralization of crotaline snake venoms from Central and South America by antivenoms produced in Brazil and Costa Rica. Toxicon, 38: 1429-1441.

30. Fernandes I, Lima EX, Takehara HA, Moura-da-Silva AM, Tanjoni I \& Gutiérrez J M (2000). Horse IgG isotypes and crossneutralization of two snake antivenoms produced in Brazil and Costa Rica. Toxicon, 38: 633-644. 